\title{
Study of Pulse Cleaning Process in Metal Fiber Filters
}

\author{
Chen Jinmei ${ }^{1}, \quad$ Xu Lei ${ }^{2}, \quad$ Tan Ping ${ }^{1}, \quad$ Li Cheng ${ }^{1}, \quad$ Pi Yanxia ${ }^{1}$ \\ ${ }^{1}$ State Key Laboratory of Porous Metals Materials, Northwest Institute for Non-ferrous Metal Research, Xi' an 710016, China; ${ }^{2}$ The \\ Construction Engineering Research Institute of PLA, Xi' an 710032, China
}

\begin{abstract}
Three kinds of FeCrAl fibers with different pore sizes were prepared by design, fabrication, sintering and repression. The pore size, resistance and capacity were tested. The results show that the initial resistance and efficiency is reduced, while the capacity is increased with the increase of pore size. The pulse-jet cleaning of fibers were operated based on VDI3926 standard at different face velocity and cleaning pressure. The result indicates sample 3 with $22 \mu \mathrm{m}$ fiber diameter have the longest cleaning lifespan. The four stages of the standard VDI3926 are completed in the face velocity of $0.06 \mathrm{~m} / \mathrm{s}$, the dust concentration of $2 \mathrm{~g} / \mathrm{m}^{3}$ and pressure drop prior to pulse-jet cleaning is $3500 \mathrm{~Pa}$. The sample increment weighing reaches $12.31 \mathrm{~g}$, the average efficiency is as high as $98.5 \%$ and consumed time is $3 \mathrm{~h}$ after 30 times artificial aging. The fiber with $22 \mu \mathrm{m}$ diameter shows the longest lifespan.
\end{abstract}

Key words: pore size; efficiency; resistance; pulse cleaning; lifespan

With the development of pollution control technology and the further research of filtering theory, metal fiber has been widely used as neotype filter material for chemical industry, metallurgy, petrochemical, equipment, environmental protection and so on ${ }^{[1,2]}$. The irregular pores of metal fiber formed by fiber interweaving and sintering, was helpful for intercepting pollutant in the fluid (high particle capture efficiency, high dust holding capacity). In addition, its advantages include high temperature, high pressure and corrosion resistant, workability, weldability, cleanable et al.

Air filters are used to control temperature, humidity and promote good indoor air quality in heating exchange, ventilation, and air conditioning (HVAC) systems ${ }^{[3]}$. Their life is finite for capture particulates and they must be replaced periodically. The air filter's useful life depends on type and size as well as the installed environment. The environment condition consists of flow rate, dust concentration, pressure, temperature, humidity et al. The filtration efficiency, pressure drop and residual pressure drop are the three main aspects of evaluation filter ${ }^{[4]}$. The residual pressure drop was formed by capturing particles that cannot be removed thoroughly after filtering and regeneration cycle. The filter need be cleaned for extending the service life when the residual pressure drop reaches a nominal pressure. The pulse cleaning is a method for reducing resistance by means of reverse air flow and vibration.

There are many publications concerning the mechanical, as the sound absorption, the heat transfer and the filtering performance of metal fiber ${ }^{[5,6]}$. However, the pulse testing has not been extensively explored ${ }^{[7]}$. The current test method had been built in according with VDI3926. In this paper, the cleaning process of different diameters of FeCrAl fiber was analyzed based on this standard. This work plays a vital role to the filter design and production.

\section{Experiment}

For these experiments, three $\mathrm{FeCrAl}$ fibers were prepared by three different fiber diameters, the fiber was designed in accordance with $80 \%$ porosity, then weighting, matching, paving, sintering at $1250{ }^{\circ} \mathrm{C}$ for vacuum and quashing to 1 $\mathrm{mm}$ thickness. The preparation of fiber need not be described in detail due to extensive exploring and application ${ }^{[8]}$. The maximum pore diameter and permeability was examined by PMS165 pore size meter (German TOPAS company)

Received date: November 14, 2016

Foundation item: National Natural Science Foundation of China (51134003); National Science and Technology Support Standard (2012BAC02B05); Shaanxi Science and Technology Co-ordination (2012K72B03-01-04)

Corresponding author: Chen Jinmei, Senior Engineer, State Key Laboratory of Porous Metals Materials, Northwest Institute for Non-ferrous Metal Research, Xi'an 710016, P. R. China, Tel: 0086-29-86231095, E-mail: chenjm82@163.com 
according to GB/T 5249-2013 ${ }^{[9]}$. The initial resistance, dust capacity, and filtration efficiency was measured by AFC131 Porous Materials Gas-solid separation Test Rig (German TOPAS company) based on EN779-2002 ${ }^{[4]}$, The test flow is $2.1 \mathrm{~m}^{3} / \mathrm{h}$, the dust concentration is $1 \mathrm{~g} / \mathrm{m}^{3}$, and the terminal pressure is $2000 \mathrm{~Pa}$.

The pulse-jet cleaning tests, when performed in accordance with VDI Guideline $3926^{[10]}$, were meant to simulate repetitive dust loading and pulse cleanings to evaluate media performance. The standard tests consisted of 30 cycles of standard loading and pulsing at a fixed pressure drop. Followed by an aging period, it subjected the media to 10000 cycles of dust loading and pulsing at $5 \mathrm{~s}$ interval. After aging, the media underwent a stabilization phase of 10 dust loading and pulsing cycles, followed by a final test of 30 cycles of dust loading and pulsing. Pulse cleanings were executed at a pressure of 0.6 MPa, with a valve opening time of $60 \mathrm{~ms}$.

In order to complete the testing in accelerated timeframe, the tests had to deviate from the VDI 3926 standard. The standard VDI test called for dust loading of $5 \mathrm{~g} / \mathrm{m}^{3}$ and a velocity of $0.033 \mathrm{~m} / \mathrm{s}$. For these tests, dust loading was decreased to $2 \mathrm{~g} / \mathrm{m}^{3}$ and velocity increased to $0.06 \mathrm{~m} / \mathrm{s}$ and $0.15 \mathrm{~m} / \mathrm{s}$. Dust selection is critical to understanding an individual application, as filter media can perform differently depending upon the type of dust that has been selected to challenge the media. VDI standards were revised to use one single test dust (Pural NF). This dust has very fine particles and does not agglomerate much, making it a challenging test dust. For these tests, however, ISO A2 Fine test dust was used to its common use across North America and Europe. Theoretically, the ISO A2 Fine is an easier dust to filter than the recommended Pural NF test dust due to large particle sizes and a tendency to agglomerate more.

\section{Results and Discussion}

\subsection{Pore size, efficiency and initial resistance}

The performance parameters of fibers are listed in Table 1. with the increase of the fiber diameter, the permeability and bubble pore size is increased, but the and initial resistance was decreased. The smaller the initial resistance is, the more pressure is required aiming to nominal pressure. These additional pressure was supplied by contain dust. So the dust holding capacity is increased. But The filter need to be cleaned when the dust holding capacity accelerates to definite extent, so the low resistance and high efficiency was expected.

\subsection{Pulse cleaning test}

The life of filter is directly related to filter area and terminal resistance, which can be extended by increasing these parameters, but the filter area could not be enlarged infinitely due to dimensions constraint, and the high resistance could lead to high energy cost. The pressure drop prior to pulse-jet cleaning of 2000, 3500 and $4000 \mathrm{~Pa}$ were used in this study based on repeated testing, and the other experimental conditions and the results are shown in Table 2.

\subsection{Influence factor on cleaning result}

The cleaning effect mainly depends on the residual pressure drop and filtration efficiency after cleaning. The residual pressure drop is created due to fiber interior dust, that could not be cleaned completely.

\subsubsection{Effect of fiber diameter on cycle life}

According to the results of pulse cleaning tests in Table 2, when the fiber diameter increases from 12 to $22 \mu \mathrm{m}$, the cycle number increases gradually from 6 to 30 times cycle on the first test condition, indicating desired effect of fiber diameter in cycle life. It is thought that the increase in cycle times is caused by the lower residual pressure drop due to the larger

Table 1 Performance of fibers

\begin{tabular}{ccccccc}
\hline $\begin{array}{c}\text { Sample } \\
\text { No. }\end{array}$ & $\begin{array}{c}\text { Fiber Diameter/ } \\
\mu \mathrm{m}\end{array}$ & $\begin{array}{c}\text { Permeability/ } \\
\mathrm{m}^{3} \cdot\left(\mathrm{m}^{2} \cdot \mathrm{kPa} \cdot \mathrm{h}\right)^{-1}\end{array}$ & $\begin{array}{c}\text { Bubble pore size/ } \\
\mu \mathrm{m}\end{array}$ & $\begin{array}{c}\text { Efficiency }(5 \mu \mathrm{m}) / \\
\%\end{array}$ & $\begin{array}{c}\text { Resistance } \\
\left(\text { below } 10 \mathrm{~m}^{3} / \mathrm{h}\right) / \mathrm{Pa}\end{array}$ & $\begin{array}{c}\text { Capacity/ } \\
\mathrm{g} \cdot \mathrm{m}^{-2}\end{array}$ \\
\hline 1 & 12 & 716 & 45 & 99.17 & 112 & 351 \\
2 & 15 & 1063 & 52 & 93.83 & 96 & 418 \\
3 & 22 & 2206 & 64 & 91.60 & 65 & 504 \\
\hline
\end{tabular}

Table 2 Conditions and results of pulse cleaning tests

\begin{tabular}{|c|c|c|c|c|c|c|c|c|}
\hline \multirow{2}{*}{ Sample No. } & \multirow{2}{*}{$\begin{array}{c}\text { Face } \\
\text { velocity } / \mathrm{m} \cdot \mathrm{s}^{-1}\end{array}$} & \multirow{2}{*}{$\begin{array}{c}\text { Concentration/ } \\
\mathrm{g} \cdot \mathrm{m}^{-3}\end{array}$} & \multirow{2}{*}{$\begin{array}{c}\text { Backflow } \\
\text { pressure/Pa }\end{array}$} & \multicolumn{4}{|c|}{ Cycle numbers } & \multirow{2}{*}{$\begin{array}{c}\text { Mass } \\
\text { increment/g }\end{array}$} \\
\hline & & & & The first & The second & The third & The fourth & \\
\hline \multirow{3}{*}{1} & 0.03 & 5 & 2000 & 6 & 0 & 0 & 0 & 6.62 \\
\hline & 0.06 & 2 & 3500 & 30 & 6 & 0 & 0 & 8.12 \\
\hline & 0.15 & 2 & 4000 & 30 & 1 & 0 & 0 & 7.43 \\
\hline \multirow{3}{*}{2} & 0.03 & 5 & 2000 & 28 & 0 & 0 & 0 & 7.83 \\
\hline & 0.06 & 2 & 3500 & 30 & 970 & 0 & 0 & 10.13 \\
\hline & 0.15 & 2 & 4000 & 30 & 23 & 0 & 0 & 9.38 \\
\hline \multirow{3}{*}{3} & 0.03 & 5 & 2000 & 30 & 34 & 0 & 0 & 9.86 \\
\hline & 0.06 & 2 & 3500 & 30 & 1402 & 10 & 2500 & 12.31 \\
\hline & 0.15 & 2 & 4000 & 30 & 129 & 0 & 0 & 11.07 \\
\hline
\end{tabular}


pore size. So the sample 3 shows the longest cycle life and the most dust holding capacity.

2.3.2 Effect of face velocity on cycle life

The residual pressure drop and the filter efficiency after 30 times cycles of $22 \mu \mathrm{m}$ fiber in different face velocity is listed in Table 3. The other test conditions keep identical parameter. The residual pressure drop shifts to higher tendency as face velocity is increased. But the efficiency almost unchanged up $98.5 \%$ when the face velocity increased from $0.03 \mathrm{~m} / \mathrm{s}$ to 0.15 $\mathrm{m} / \mathrm{s}$. The reason is that the more dust particle, which can't be clear due to higher compressive stress, will enter fiber media resulting in resistance increase and lifespan reduction. In addition large surface velocity will cause excessive energy consumption for cleaning frequently. So the face velocity should not be too fast in the actual application.

2.3.3 Effect of pressure drop prior to pulse-jet cleaning on cycle life

The pressure drop prior to pulse-jet cleaning of $2000 \mathrm{~Pa}$ to $4000 \mathrm{~Pa}$ were used in these tests. As seen in Table 2, the sample 3 at $3500 \mathrm{~Pa}$ pulse cleaning shows the longest lifespan and the most holding capacity $12.31 \mathrm{~g}$. So this pressure should be neither small nor big. The fiber media couldn't display maximum lifespan if too small. In contrast, the cleaning process will not continue when the residual pressure drop no longer increase but can not arrived end pressure because of filter cake.

\subsection{Cleaning process analysis}

As the fiber is subjected to dust loading and pulse cleaning cycles, particles gradually build up on and in the fiber. Fiber that releases dust more effectively will show less buildup, in residual pressure drop, leading to longer times between pulsing potentially longer fiber life, and potential energy savings. The balance of adsorption force and gravity could be destroyed by the reverse airflow leading to dust abscission. In addition, the dust gravity and the inertia force in the process of fiber's expansion and contraction make the dust layer fall off due to dust layer tension free. The greater the inertia is, the better the cleaning effect is.

Table 2 shows the results of pulse cleaning tests. The sample 3 have the longest lifespan at velocity of $0.06 \mathrm{~m} / \mathrm{s}$, dust concentration of $2 \mathrm{~g} / \mathrm{m}^{3}$, pressure drop prior to pulse-jet cleaning of $3500 \mathrm{~Pa}$. It is the only one completing the whole process according to VDI3926. But the 1402 times are far less than standard 10000 times on artificial aging phase, which shows that the VDI3926 is not suitable for metal filter.

Fig. 1 shows the curve of time versus residual pressure drop in the first 30 times cycles, which is one of the key parameters. The real cleaning behavior was analyzed. For instance Fig.1a progressive or digressive increase of the pressure drop during a filtration cycle is observed. Responsible for this are the compressive stresses impressed on the filter cake by the pressure drop. The filter cake is compressed and the porosity of the cake is reduced resulting in an increased flow resistance. Every cycle period is strongly reduced as compared to the previous. Reduction of the cycle periods is caused by the increase of the residual pressure drop because of internal dust deposition and superficial incomplete cleaning.

From Fig. 1, it clearly indicates the cycle time is gradually increased from sample 1 to sample 3 , and sample 3 seems to be adding residual pressure drop more quickly. It takes $1 \mathrm{~h}$ to reach $3500 \mathrm{~Pa}$, while it takes about $30 \mathrm{~min}$ for sample 1 and 2 at first cycle. At the same time, the residual pressure drop decreases to $80 \mathrm{~Pa}$ for sample 3, but only $1000 \mathrm{~Pa}$ and $750 \mathrm{~Pa}$ for sample 1 and 2 after the first pulse-jet cleaning end. As sample 3 starts at a much lower initial pressure drop, it is automatically at an advantage over others. Three samples consume time are $1 \mathrm{~h}, 102 \mathrm{~min}, 3 \mathrm{~h}$, respectively to complete the first phase. This also indicates that the sample 3 has the best service life.

Table 3 Result of sample 3 under different face velocity

\begin{tabular}{cccc}
$\begin{array}{c}\text { Face velocity } \\
/ \mathrm{m} \cdot \mathrm{s}^{-1}\end{array}$ & $\begin{array}{c}\text { Initial resistance } \\
\text { pressure/kPa }\end{array}$ & $\begin{array}{c}\text { Residual pressure } \\
\text { drop/kPa }\end{array}$ & $\begin{array}{c}\text { Efficiency } \\
\text { after } 30 \text { times } / \%\end{array}$ \\
\hline 0.03 & 15 & 342 & 98.6 \\
0.06 & 26 & 423 & 98.5 \\
0.15 & 32 & 516 & 98.8 \\
\hline
\end{tabular}
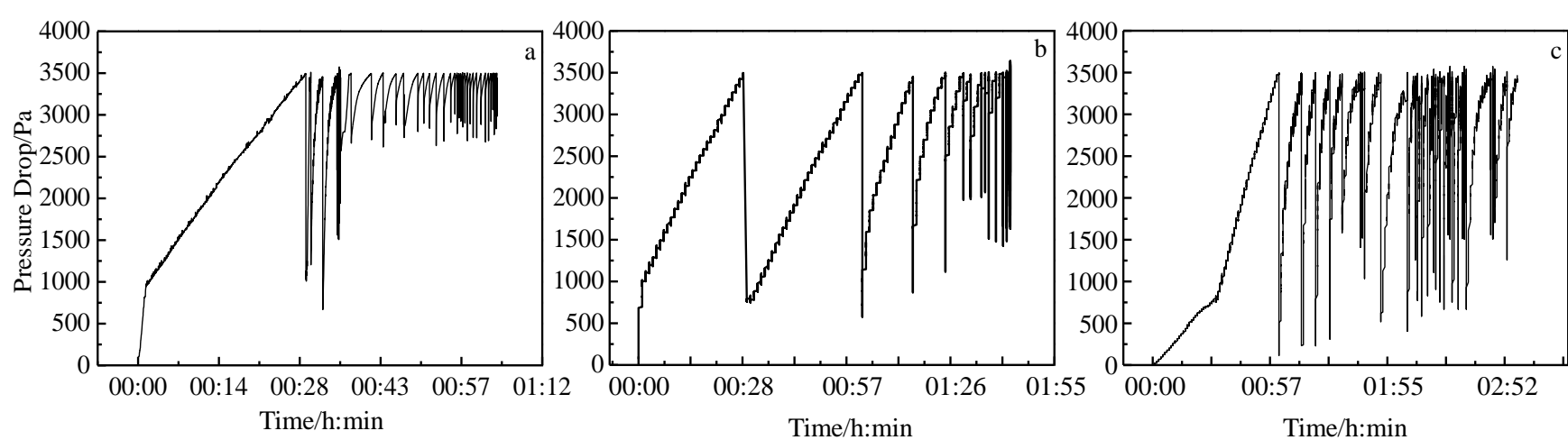

Fig.1 Pressure drop vs time in 30 times cleaning cycles: (a) sample 1, (b) sample 2, and (c) sample 3 


\section{Conclusions}

1) In the same flow rate, the smaller the initial resistance is, the greater the capacity is and the lower the efficiency is. With the fiber diameter increasing, the efficiency is almost not changed when the sample surface is covered with filter cake.

2) The fiber diameter, the face velocity, the terminal differential pressure have great influence on cycle life. The cleaning effect is the best on the large diameter fiber, the suitable face velocity and terminal differential pressure.

3) It should be noted that these results are very preliminary, and artificially accelerated. The tests show that sample 3 maintains their full integrity during pulse cleaning at the face velocity of $0.06 \mathrm{~m} / \mathrm{s}$, dust concentration of $2 \mathrm{~g} / \mathrm{m}^{3}$ and the pressure drop prior to pulse-jet cleaning of $3500 \mathrm{~Pa}$. After artificial aging, the weight increment is $12.31 \mathrm{~g}$, the average efficiency is as high as $98.5 \%$ and artificial aging consumed time $3 \mathrm{~h}$. This fiber shows the longest lifespan.

4) The VDI3926 are suitable for woven, non-woven fabrics, needle felts and non-textile materials not for metal fiber filter. So the new standard will be considered for future working. Experiment condition and test parameters should be taken into account as important object. At the same time the execution of the test should not be too time-consuming and easy to handle.

\section{References}

1 Rubow K L, Ph D, Stange L L. The 2nd China International Filtration Conference[C]. Shanghai, 2002

2 Zhu Neng, Zhao He. Journal of Gas \& Heat[J], 2005, 25: 1 (in Chinese)

3 Liu L H, Wang S H. Filter \& Separator[J], 2000, 10(4): 8 (in Chinese)

4 EN779-2002[S]. 2002

5 Qiao J H, Xi Z P, Tang H P et al. Rare Metal Materials and Engineering [J], 2009, 38(3): 267 (in Chinese)

6 Tang H P, Zhu J H, Wang J Y et al. Rare Metal Materials and Engineering[J], 2007, 36(12): 2220 (in Chinese)

7 Liu J H, Pan Y. Liaoning Chemical Industry[J], 2010: 39(5): 511 (in Chinese)

8 Zhang J, Li C, Wu X et al. Rare Metal Materials and Engineering[J], 2007, 36(3): 378 (in Chinese)

9 GB/T5249-2013[S]. 2013

10 VDI3926-2004[S]. 2004

\title{
金属纤维毡的反吹清灰过程研究
}

\author{
陈金妹 ${ }^{1}$, 徐 䂞 $^{2}$, 谈 萍 ${ }^{1}$, 李 程 $^{1}$, 皮艳霞 ${ }^{1}$ \\ (1. 西北有色金属研究院 金属多孔材料国家重点实验室, 陕西 西安 710016) \\ (2. 总后建筑工程研究所, 陕西 西安 710032)
}

摘 要: 选用 3 种不同丝径的 $\mathrm{FeCrAl}$ 纤维丝, 通过配毡、铺毡、烧结和压制等过程制备出 3 种不同孔径的 $\mathrm{FeCrAl}$ 纤维廷, 分析了孔径 对过滤效率, 初阻力和容尘量的影响。发现孔径越大, 初阻力变小, 容尘量增加, 过滤效率降低。部分参数参考 VDI3926 标准对 3 种 纤维廷进行了脉冲清灰测试, 在面速为 $0.06 \mathrm{~m} / \mathrm{s}$, 粉尘浓度为 $2 \mathrm{~g} / \mathrm{m}^{3}$, 反吹压差为 $3500 \mathrm{~Pa}$ 时, 丝径为 $22 \mu \mathrm{m}$ 的样品 3 表现出最好的清 灰效果, 样品增重达 $12.31 \mathrm{~g}$, 形成滤饼后的效率高达 $98.5 \%$, 30 次人工老化共耗时近 $3 \mathrm{~h}$, 寿命最长。

关键词: 孔径; 效率; 阻力; 脉冲清灰; 寿命

作者简介：陈金妹，女，1982 年生，高级工程师，西北有色金属研究院金属多孔材料国家重点实验室，陕西 西安 710016，电话： 029-86231095, E-mail: chenjm82@163.com 